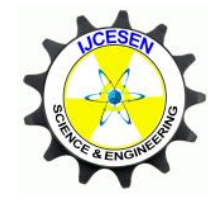

Copyright (C) IJCESEN
International Journal of Computational and

Experimental Science and $\boldsymbol{E N g i n e e r i n g}$

(IJCESEN)

Vol. 5-No.1 (2019) pp. 43-47

http://dergipark.gov.tr/ijcesen

Research Article

\title{
Decreasing the Cogging Torque using Virtual Positive Impedance Based Active Damping Control Method for PMSMs
}

\author{
Ahmet AKSÖZ1,*, Ali SAYGIN² \\ ${ }^{1}$ Cumhuriyet University/ Mechatronics Engineering Department, Sivas, TURKEY \\ ${ }^{2}$ Gazi University/ Electrical and Electronics Engineering Department, Ankara, TURKEY \\ * Corresponding Author : aaksoz@cumhuriyet.edu.tr \\ ORCID: $0000-0002-2563-1218$
}

\section{$\underline{\text { Article Info: }}$ \\ DOI: $10.22399 /$ ijcesen.522865 \\ Received : 05 February 2019 \\ Accepted : 27 February 2019}

\section{$\underline{\text { Keywords }}$}

ADC

PMSM

VPI.

\begin{abstract}
:
In this paper, active damping control based virtual positive impedance for a PMSM driver is proposed. The proposed model is assumed to achieve the better motor current with a better harmonic response. 6 switches can be employed in the design of the driver to obtain high performance with a simultaneous reduction in the motor current harmonics and thus the torque ripple of PMSM. However, the reduction of input current harmonics is very important to operate the PMSM with less cogging torque. The proposed concept offers a significant decreasing in harmonics. Thus, the effect of VPI on the cogging torque can be understood. The inverter with a Field Oriented Control (FOC) method operates in 3-phase and 20 $\mathrm{kHz}$ switching frequency. The PMSM motor is fed by the inverter. The VPI based active damping control for the motor drive is discussed to confirm the performance of the proposed method. The simulation results based on MATLAB are provided to validate the proposed control strategy.
\end{abstract}

\section{Introduction}

Last trends in control methods area show that a better control approach supplies more desired results [1]. It means better control is the more efficiently system [1-5]. Especially, motor drivers must have more efficient. Because of the fact that complicated linear or nonlinear loads are used more than ever. Also using multi drivers cause more unexpected situation. Both variable speed drivers and adjustable speed drivers have the embedded diode-rectifier. It has high nonlinear characteristic due to nonsinusoidal input currents. However, this nonlinear characteristic leads more cogging torque on the motor, even if it is designed very well $[6,7]$. In order to achieve longer lifetime drivers, the modulation of switch and inverter design must be succeeded beside the control method [8-11].

This paper investigates the cogging torque issue of PMSM. Using active damping control (ADC) and virtual positive impedance method (VPI), increasing the performance of inverter is investigated. Thanks to desired inverter behaviour, the cogging torque of the motor can be decreased $[12,13]$.

A new inverter model is simulated according to the control method. Two case are designed and compared for understanding results of this control method on proposed cases. Case 1 is classical field oriented control (FOC) method without ADC based VPI method. And using ADC based VPI in FOC is case 2. After the simulation results, the DC bus voltage and motor currents are discussed.

\section{System Description}

\subsection{Driver of the PMSM}

This driver system, as shown in Fig. 1, consists of 5 divisions. They are a grid connected autotransformer, a diode rectifier, DC link capacitors, an inverter and a sensor card In Fig. 1, $400 \mathrm{~V}-48 \mathrm{~Hz}$ grid supplied the. 


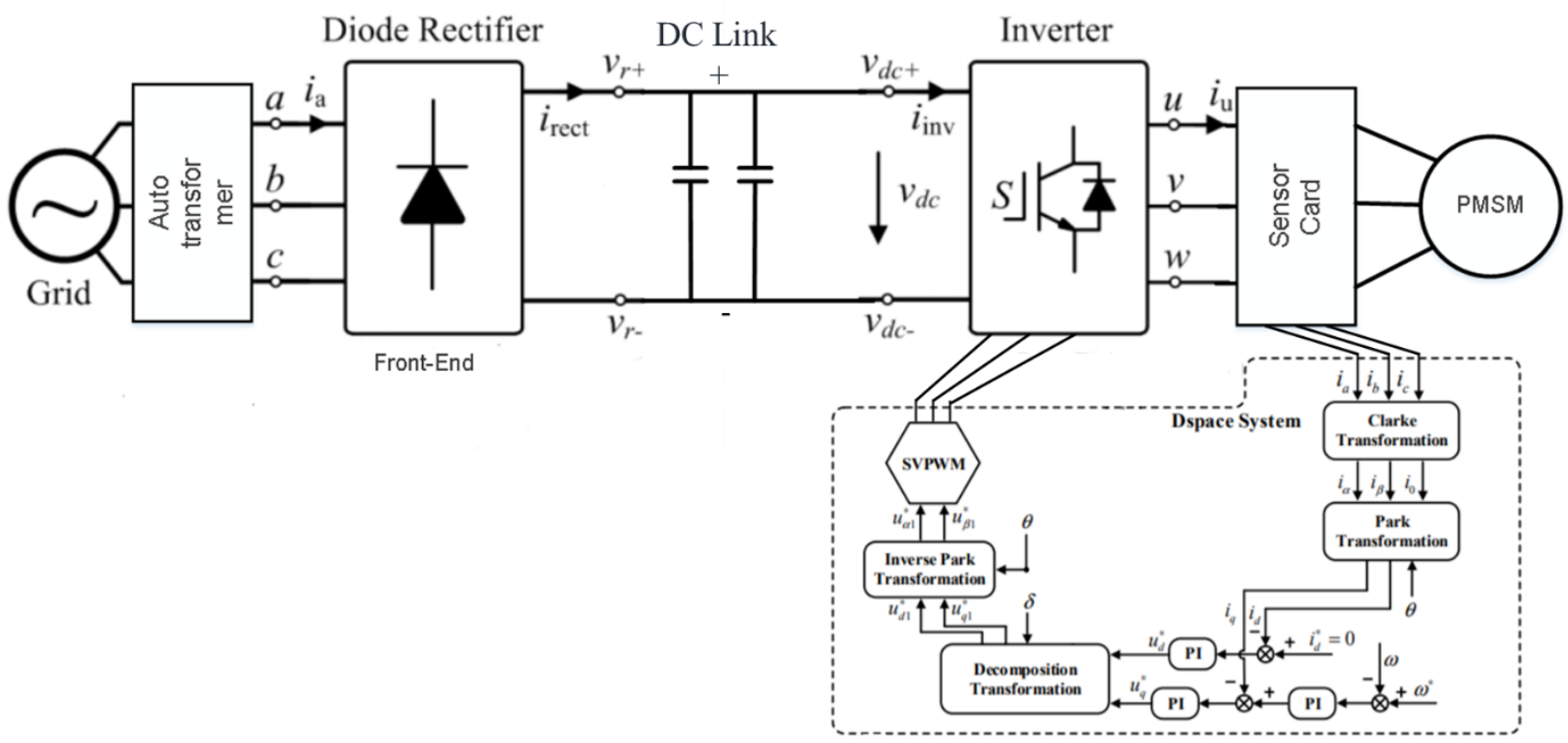

Figure 1. Driver Block Diagram.

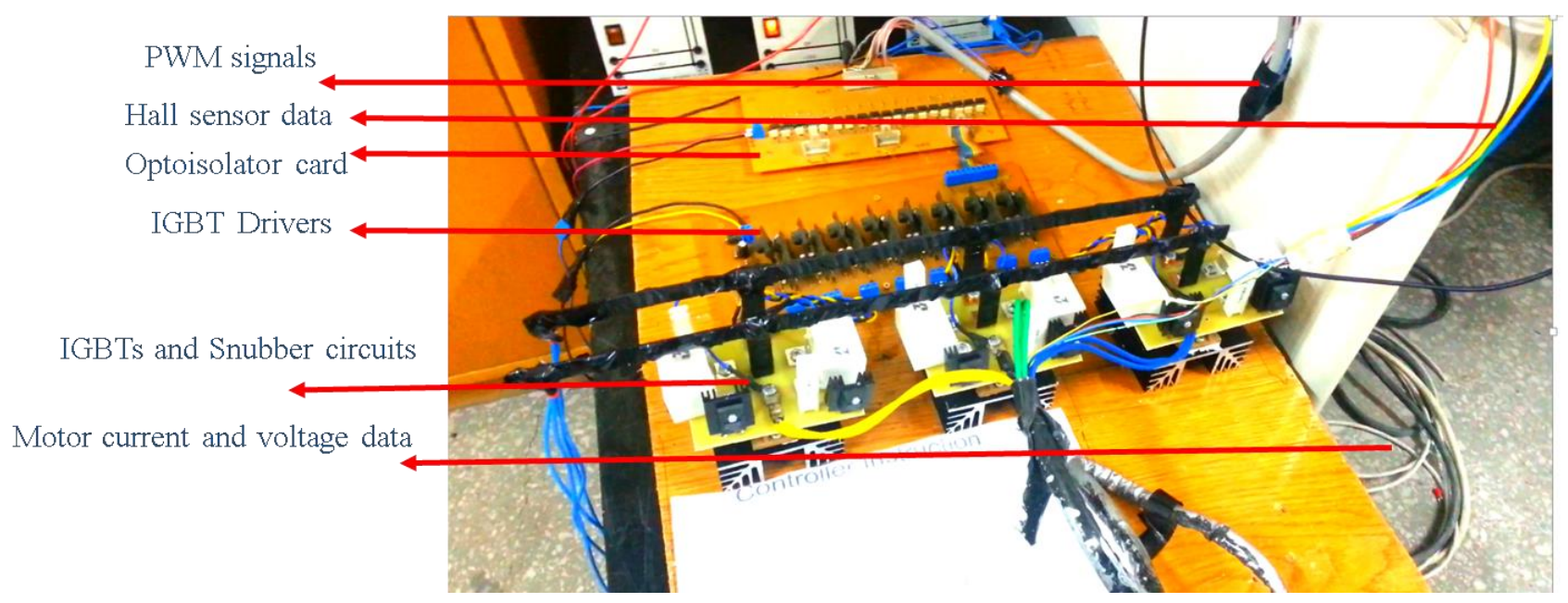

Figure 2. Inverter System

autotransformer transforms to voltage value from $400 \mathrm{~V}$ to $48 \mathrm{~V}$. Then the diode rectifier rectifies AC $48 \mathrm{~V}$ to DC $48 \mathrm{~V}$. Thanks to DC link capacitors, the DC voltage value gets closer to constant $48 \mathrm{~V}$ with some voltage ripples. The inverter system feds the motor with AC 50V. Lastly, the motor currents are measured from sensor card and transferred to DSpace system. PWM signals are generated using control method with or without ADC based VPI on d-q frame.

\subsection{Inverter System}

Designed and simulated inverter system is given in Fig 2. PWM signals, hall sensor data cables, an optoisolator card, IGBT drivers, IGBTs and snubber circuits and motor measuring data cables can be seen below. Generated PWM signals are isolated from the optoisolator card. Then IGBT switches produce the AC voltage thanks to these PWM signals. Here, hall sensor data can be used when sensored position control is achieved. The block diagram of this inverter is illustrated in Fig 3 Above, the speed control and the position control can be desired in this inverter. But, only the speed control is realized in this study.

\subsection{Control Methods}

The virtual impedance method supplies less voltage ripples on DC link voltage. Thus, the inverter can be more stable thanks to more stable DC link voltage value. The VPI block diagram is displayed in Fig 4. Using VPI method, DC link voltage feedback go into 


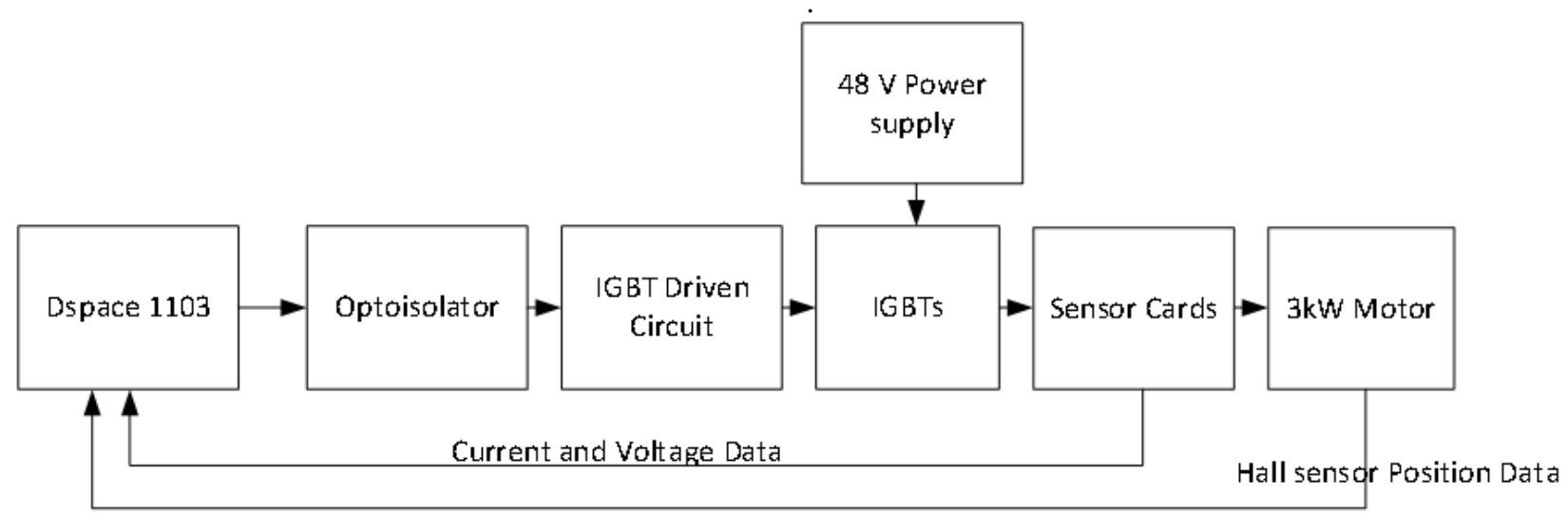

Figure 3. Block Diagram of Inverter

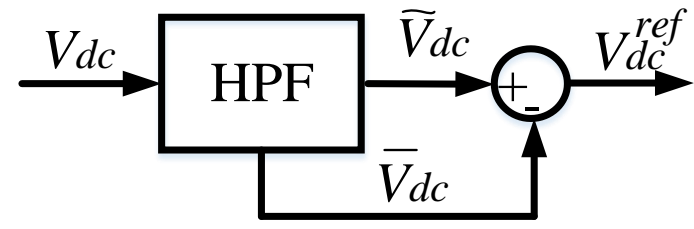

Figure 4. Block Diagram of VPI method.

HPF block. Firstly, the high pass process but totally the low pass operation is realized in this block. The DC reference voltage value ise used for generating PWM signals. VPI method in FOC control and the FOC control block diagram in DSpace and simulation is given in Fig. 5. Clarke-Park Transformation and PI control are used in this FOC block.

\section{Simulation of the System}

Two case are designed in Matlab by using Fig. 1, Fig. 2, Fig. 3, Fig. 4 and Fig. 5. The main difference of two cases is using ADC based VPI method in case 2 . Thus, the cogging torque results are obtained from two cases. Table 1 gives the cogging torque results of two cases. Cogging torque results of $3 \mathrm{~kW}-48 \mathrm{~V}$ PMSM motor are represented in Table 1. The cogging torque value of Case 1 is $0.444 \mathrm{Nm}$. When using ADC based VPI method, the cogging torque value is $0.327 \mathrm{Nm}$ for Case 2. Although two parallel $5 \mathrm{e}-2 \mathrm{~F}$ capacitor filter the diode rectifier output, voltage ripples on the DC link voltage cause worse trapezoidal voltage signals in output of the inverter. But better voltage output and better results are obtained when ADC based VPI is used as seen in Fig. 6. This figure and results are come into by using Eq. 1,
Table 1. Cogging Torque Results.

\begin{tabular}{|c|c|}
\hline Models & Cogging Torque (Nm) \\
\hline Case 1 & 0.444 \\
\hline Case 2 & 0.327 \\
\hline
\end{tabular}

Eq. 2, Eq. 3 and Eq. 4.

$T_{\operatorname{cog}}=\frac{1}{2} \emptyset_{g}^{2} \frac{d R}{d \theta}$

where $\emptyset_{g}$ is the air gap flux, $d R$ is air gap reluctance and $d \theta$ is angle of rotation. Periodically changing the reluctance of the air gap causes periodically changing of the cogging torque. Because of this periodic variation, the value of the cogging torque can be calculated by the Fourier series.

$T_{c o g}\left(\theta_{m}\right)=\sum_{k=1}^{\infty} T_{k} \sin \left(k N_{c} \theta_{m}+\varphi_{k}\right)$

where the rotor position is $\theta_{m}, T_{k}$ is the amplitude of $\mathrm{k}$ th harmonic, $\varphi_{k}$ is the phase angle of $\mathrm{k}$ th harmonic and $N_{c}$ is the least common multiple of rotor pole number and stator slot number. Also, the density of the surface flux of ideal slotless motor can be expressed as,

$$
\begin{aligned}
& B_{r l}(\theta)=\sum_{n=1,3,5, \ldots}^{\infty} 2 \frac{\mu_{0} M_{n}}{\mu_{r}} \frac{n p}{(n p)^{2}-1}\left(\frac{R_{m}}{R_{s}}\right)^{n p+1} \\
& {\left[\frac{(n p-1)+2\left(\frac{R_{m}}{R_{s}}\right)^{n p+1}-(n p+1)\left(\frac{R_{m}}{R_{s}}\right)^{2 n p}}{\frac{\mu_{r}+1}{\mu_{r}}\left[1-\left(\frac{R_{r}}{R_{s}}\right)^{2 n p}\right]-\frac{\mu_{r}-1}{\mu_{r}}\left[\left(\frac{R_{m}}{R_{s}}\right)^{2 n p}-\left(\frac{R_{r}}{R_{m}}\right)^{2 n p}\right]} \cos (n p \theta)\right.}
\end{aligned}
$$




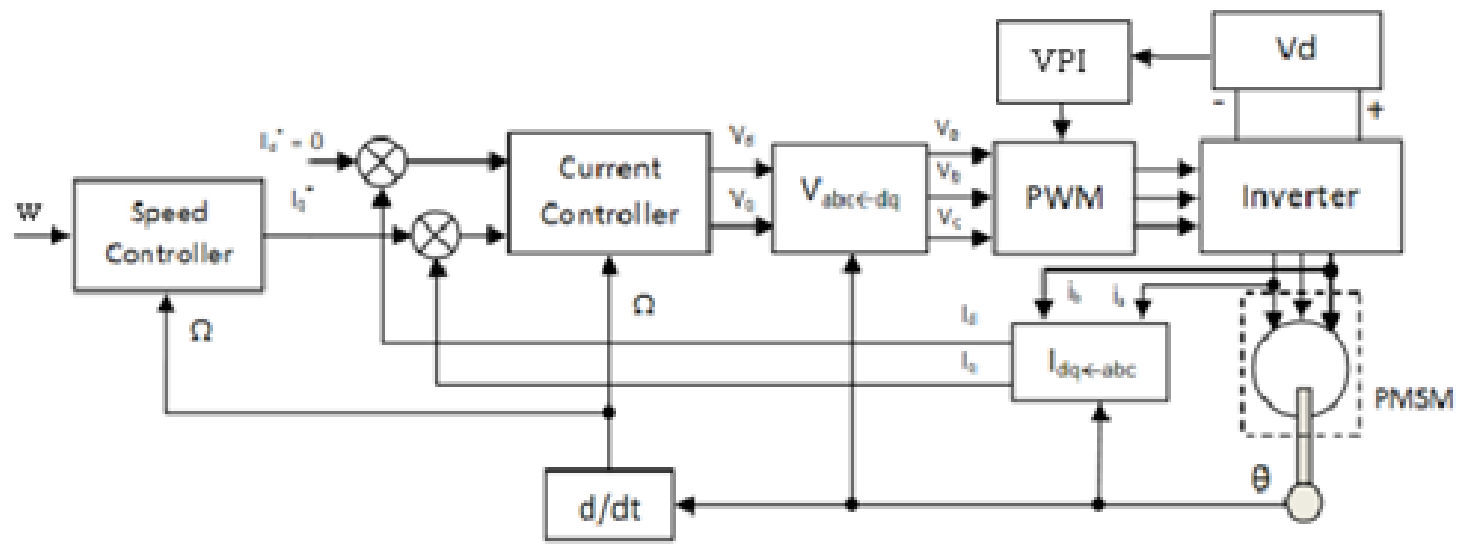

Figure 5. FOC Control Block Diagram

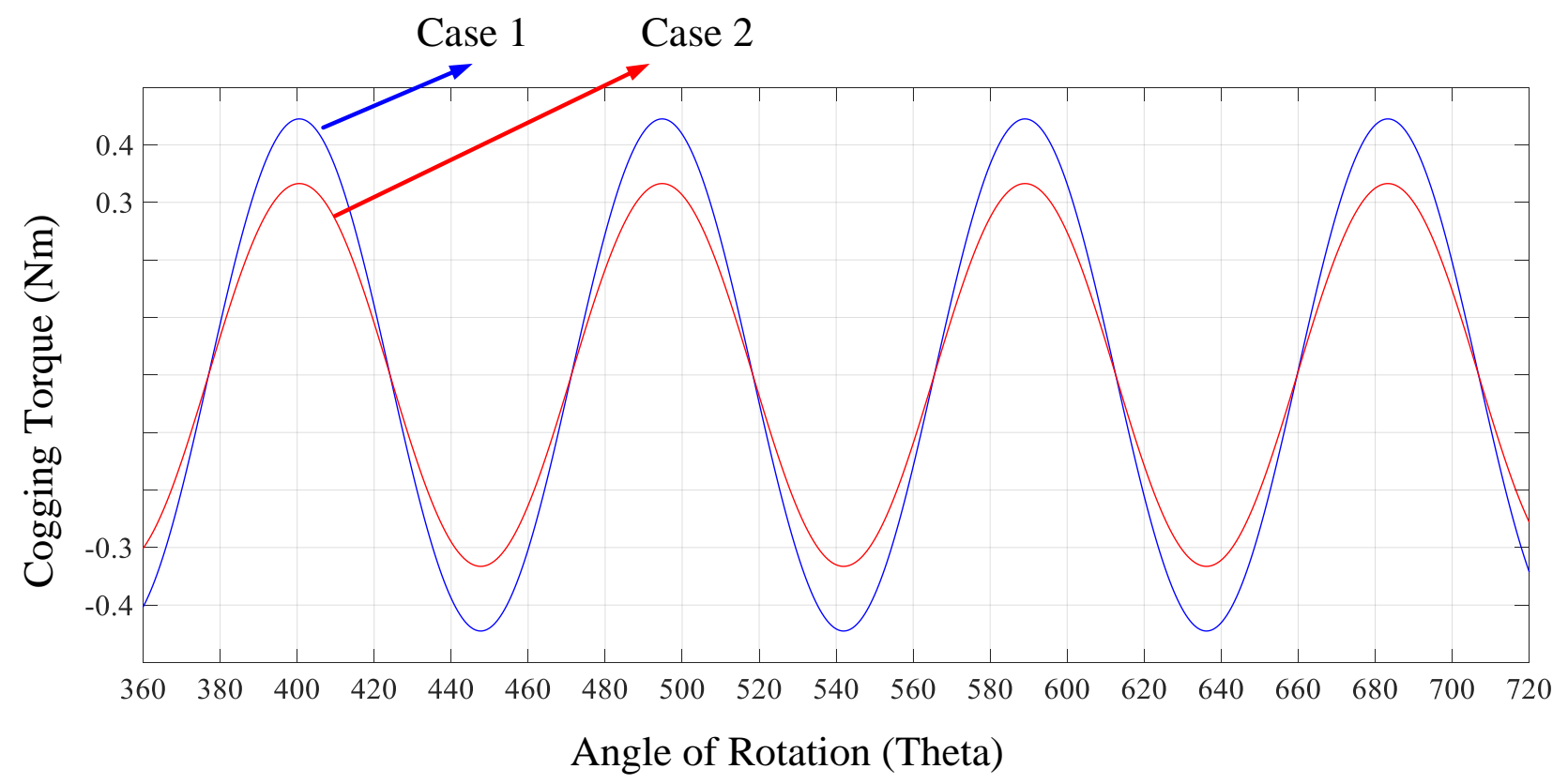

Figure 6. Cogging Torque of Two C

$M_{n}=2\left(\frac{B_{r}}{\mu_{0}}\right) \alpha_{p} \frac{\sin \left(\frac{n \pi \alpha_{p}}{2}\right)}{\frac{n \pi \alpha_{p}}{2}}$

where $\mathrm{Rm}$ is the outer radius of the magnet, $\mathrm{Rs}$ is the outer radius of the stator, $\mathrm{Rr}$ is the outer radius of the rotor, $\mathrm{p}$ is the double pole number and $\alpha \mathrm{p}$ is the pole step.

\section{Conclusion}

The active damping control based virtual positive impedance is developed for a PMSM driver is FOC control. After two cases are designed, the better motor current with less voltage ripple on the DC link voltage is get by ADC based VPI method. In order to achieve longer lifetime and high performance motor driver, it must be more stable with less voltage ripple and less cogging torque. Simulated cases show that the more stable driver and the less cogging torque can be obtained using ADC based VPI method in FOC.

\section{Acknowledgement}

Authors thanks to TUBITAK 2211-A (Grant number: 1649B031400107).

\section{References}

[1] A. Saygin, A.M. Rashid, Position control of a turret using LabVIEW, Acta Physica Polonica A (2017) 132 (3), pp. 970-973. DOI: 10.12693/APhysPolA.132.970

[2] S. Altuntaş, H. Hapoğlu, S. Ertunç, M. Alpbaz, Experimental Self-Tuning Proportional Integral Derivative $\mathrm{pH}$ Control: Application to a Bioprocess, Acta Physica Polonica A (2017) pp 1006. DOI: 10.12693/APhysPolA.132.1006 
[3] M.K. Döşoğlu, U. Güvenç, Y. Sönmez, C. Yılmaz, Enhancement of demagnetization control for lowvoltage ride-through capability in DFIG-based wind farm, Electrical Engineering, (2018) 100 (2), pp. 491-498. DOI: $10.1007 / \mathrm{s} 00202-017-0522-6$

[4] N.G. Adar, R. Kozan, Comparison between Real Time PID and 2-DOF PID Controller for 6-DOF Robot Arm, Acta Physica Polonica A (2016) pp 269. DOI:10.12693/APhysPolA.130.269

[5] N.G. Adar, A. Egrisogut Tiryaki, R. Kozan, Real Time Visual Servoing of a 6-DOF Robotic Arm using Fuzzy-PID Controller, Acta Physica Polonica A (2015) pp B-348. DOI: 10.12693/APhysPolA.128.B-348

[6] Y. Sarikaya, H. Apaydin, Ş. Kıtış, A Hydrolysis System Design and Ana-lysis for Vehicles with Microprocessor Based and PWM Controlled Card, Acta Physica Polonica A (2015) pp B-211. DOI: 10.12693/APhysPolA.128.B-211

[7] A. Saygin, A. Aksoz and E. N. Yilmaz, A different model of WECS connected to smart grid through matrix converter, 2016 4th International Istanbul Smart Grid Congress and Fair (ICSG), Istanbul (2016), pp. 1-5. DOI: 10.1109/SGCF.2016.7492419

[8] E.N. Yilmaz, A. Aksoz and A. Saygin, Electr Eng (2018).DOI: 10.1007/s00202-018-0734-4

[9] E. Can, H.H. Sayan, A novel SSPWM controlling inverter running nonlinear device, Electrical Engineering, (2018) 100 (1), pp. 39-46. DOI: 10.1007/s00202-016-0480-4

[10] E. Can, H.H. Sayan, The increasing harmonic effects of SSPWM multilevel inverter controlling load currents investigated on modulation index, Tehnicki Vjesnik, (2017) 24 (2), pp. 397-404. DOI: 10.17559/TV-20151020134629

[11] A. Saygin, A. Kerem, Speed control of an induction motor by 6-switched 3-level inverter, Open Physics, (2017) 15 (1), pp. 1072-1076. DOI: 10.1515/phys2017-0138

[12] R. Kiliç, Determination of Imbalance Problem in Electric Motor and Centrifugal Pump by Vibration Analysis, Acta Physica Polonica A (2016) pp487. DOI:10.12693/APhysPolA.130.487

[13] A. Saygin and A. Aksoz, Design optimization for minimizing cogging torque in Axial Flux Permanent Magnet machines, 2017 International Conference on Optimization of Electrical and Electronic Equipment (OPTIM) Brasov (2017), pp. 324-329. DOI: 10.1109/OPTIM.2017.7974991 